\title{
Glutamic Acid Decarboxylase in the Striate Cortex of Normal and Monocularly Deprived Kittens ${ }^{1}$
}

\author{
MARK F. BEAR, ${ }^{2}$ DONALD E. SCHMECHEL, ${ }^{3}$ AND FORD F. EBNER ${ }^{4}$ \\ Center for Neural Science, Brown University, Providence, Rhode Island 02912
}

\begin{abstract}
Degeneration of the thalamic fibers in the visual cortex of turtles leads to an increase in the numerical density of cortical synapses with flattened vesicles and symmetrical membrane differentiations (Smith, L. M., and F. F. Ebner (1980) Soc. Neurosci. Abstr. 6: 328). This change correlates with an increase in the cortical activity of glutamic acid decarboxylase (GAD), the synthetic enzyme for $\gamma$-aminobutyric acid (GABA). These data are consistent with the hypothesis that removal of thalamic input activity is the stimulus for cortical GABAergic neurons to form new synapses. Pharmacological evidence suggests that even simple environmental deprivation may induce a similar increase in the numerical density of GABAergic synapses in kitten striate cortex (Duffy, F. H., S. R., Snodgrass, J. L. Burchfiel, and J. L. Conway (1976) Nature 260: 256-257). We have examined this possibility in monocularly deprived kittens using methods to localize and measure GAD.
\end{abstract}

GAD in kitten striate cortex was localized using immunocytochemistry. GAD-positive cells were found in all layers and were uniformly distributed in layers II to VI. Immunoreactivity associated with axon terminals (puncta), in contrast, was laminated with a distinct band in layer IV. Monocular deprivation (MD), by either unilateral enucleation or lid closure, had no detectable effect on the distribution of GAD in striate cortex. The band of layer IV puncta remained uniform even under conditions that produced alterations in layer IV cytochrome oxidase activity.

We measured GAD activity in homogenates of striate cortex to address the possibility that MD causes an absolute change in the density of GABAergic synapses. Again, however, GAD activity in the binocular and monocular segments of striate cortex was found to be unaffected by early enucleation.

Received July 12, 1984; Revised October 29, 1984;

Accepted November 8, 1984

${ }^{1}$ This research was supported by United States Office of Naval Research Contract N0014-81-K-0136. We gratefully acknowledge Dr. E. Mugnaini for helpful suggestions regarding the immunocytochemistry, Dr. R. L. Patrick for help in establishing the glutamic acid decarboxylase assay, and Drs. L. N. Cooper and I. T. Diamond for their support and encouragement. Special thanks to Kim Landay for technical assistance, and to Dr. M. Paradiso for critically reading the manuscript.

${ }^{2}$ Present address: Max-Planck-Institut fur Hirnforschung, 6 Frankfurt/M. Niederrad, Deutschordenstrasse 46, Federal Republic of Germany.

${ }^{3}$ Present address: Division of Neurology, Duke University, Durham Veterans Administration Medical Center, Durham, NC 27705.

${ }^{4}$ To whom correspondence should be addressed, at Division of Biology and Medicine, Box G, Brown University, Providence, RI 02912.
These data suggest two conclusions: first, that the numerical density of GABAergic synapses in visual cortex is not regulated directly by thalamic activity, and second, that changes in GABAergic synapse density do not account for the ocular dominance shift observed in kitten striate cortex after MD.

GABAergic circuitry appears to be an essential feature of neocortical organization (Emson and Hunt, 1981). The neocortex of every mammalian species studied has been shown to possess neurons that synthesize and presumably release GABA. GABAergic neurons are even present in the cerebral cortex of primitive reptiles (Smith and Ebner, 1980), suggesting that they existed in the pallium of an ancestor common to all mammals. Iontophoresis of GABA in the neocortex hyperpolarizes most neurons (Krnjevic and Schwartz, 1966, 1967; Dreifus et al., 1969), an effect that can be blocked by the GABA antagonist bicuculline (Curtis and Felix, 1971; Sillito, 1975). The fact that most IPSPS recorded intracellularly from cortical neurons are also blocked by bicuculline but not by strychnine, a glycine antagonist (Johnston, 1976), suggests that GABA is the primary inhibitory neurotransmitter in the cerebral cortex.

Available data indicate that GABA is synthesized and released from cortical interneurons. For example, the activity of glutamic acid decarboxylase (GAD), the synthesizing enzyme for GABA, is not reduced in cortex by extensive subcortical lesions. In contrast, destruction of cortical neurons with kainic acid drastically reduces cortical GAD activity and GABA uptake (Johnston el al., 1981). Also, immunocytochemical localization of GAD is restricted to the nonpyramidal cells in cerebral cortex (Ribak, 1978) long assumed to be local circuit neurons (Ramón y Cajal, 1911). Electron microscopy of GAD-immunoreactive cortical cells reveals that they have smooth, beaded or sparsely spinous dendrites, and that their axon terminals contain flat (pleomorphic) vesicles and make symmetrical (Gray's type 2) synaptic membrane differentiations (Ribak, 1978; Freund et al., 1983). Synapses with this morphology constitute about $30 \%$ of all synapses in cat visual cortex (Winfield, 1981) and are commonly observed on dendritic shafts and on neuronal perikarya.

A number of recent lines of evidence suggest that GABAergic circuitry will change considerably in response to brain lesions. For example, Rutledge (1978) documented increased density of flatsymmetrical (FS) synapses in undercut cat neocortex. Smith and Ebner (1980) report that thalamcctomy causcs a similar increase in FS synapses in turtle cortex that correlates with an increase in GAD activity. Increases in GAD activity have been noted also in the dentate gyrus after lesions of the entorhinal cortex (Nadler et al., 1974), in the olfactory tubercle after removal of the olfactory bulb (Gilad and Reis, 1979), and in the striatum after lesions of the nigrostriatal pathway (Vincent et al., 1978). These data raise the possibility that GABAergic neurons generally may respond to deafferentiation by forming new synapses.

Even relatively subtle manipulations of sensory input may be 
sufficient to evoke an increase in GABAergic synapses in visual cortex. For example, pharmacological evidence suggests that GABAergic mechanisms contribute to the cortical response to monocular deprivation (MD). Normally, MD of young kittens shifts the ocular dominance of visual cortical neurons dramatically toward the open eye (Hubel and Wiesel, 1970). However, administration of intravenous bicuculline to monocularly deprived kittens restores responsiveness to stimulation of the deprived eye in $50 \%$ of visual cortical neurons (Duffy et al., 1976). Bicuculline applied locally to cortical cells also partially reverses the effects of MD (Burchfiel and Duffy, 1981). These results suggest that the GABAergic interneurons of striate cortex respond to MD by tonically inhibiting cells that retain functional connections with the deprived eye. Noncompetitive binocular deprivation results in changes in cortical physiology that are also consistent with an increased level of inhibition. For example, as few as $36 \%$ of cortical neurons are visually responsive in binocularly deprived cats (Singer and Tretter, 1976). A similar effect has been noted in the deprived monocular segment of monocularly deprived kittens (Wilson and Sherman, 1977). That is, only one-third of the neurons in the deprived segment are visually responsive. Sillito (1975) documented in normal cats that visually unresponsive cells may be "unmasked" by iontophoretic bicuculline. Thus, the evidence supports the idea that many of the unresponsive cells in visually deprived kittens are being suppressed by GABAergic inhibition. Together, these data led us to hypothesize that in kitten striate cortex the GABAergic neurons respond to sensory deprivation by forming new synapses. This hypothesis explicitly predicts that the numerical density of GABAergic synapses will increase in zones of cortex that are deprived of normal levels of thalamic input activity; in the case of MD (by either lid closure or enucleation), these zones correspond to the monocular segment contralateral to the deprived (enucleated) eye, as well as to the closed eye (enucleated eye) ocular dominance columns.

In this paper, we describe the results of experiments designed to test this hypothesis. To examine the distribution of GABAergic synapses, we have localized GAD in sections of striate cortex using immunocytochemistry. Although immunocytochemistry is not a quantitative measure, we reasoned that changes restricted to deprived ocular dominance zones should be readily detected with this method. As a quantitative estimate of GABAergic synapse density, we have biochemically measured GAD enzyme activity in homogenates of striate cortex. Our justification for using this assay as an estimate of synaptic density stems from the observation that GAD activity (1) closely parallels GABA receptor binding in developing rat cortex (Coyle and Enna, 1976) and (2) correlates with changes in the density of FS-type synapses in turtle cortex (Smith and Ebner, 1980). We report, contrary to our expectation, that MD (by urilateral enucleation) is not an adequate stimulus for a detectable change in the density of GABAergic synapses in kitten striate cortex. These results suggest that the ocular dominance shift after MD does not require sprouting of GABAergic interneurons.

\section{Materials and Methods}

Animals. In all, 33 animals were used in this investigation: 16 for immu nocytochemistry and 17 for GAD biochemistry. Of these, 22 were monocu larly deprived by unilateral enucleation. Enucleations were performed under ketamine anesthesia; control kittens were anesthetized at the same time. We chose enucleation over lid suture to avoid any ambiguities that might result from partial lid opening. Furthermore, enucleation was the manipulation of choice in the context of testing our hypothesis because it completely silenced the "deprived eye" channel to striate cortex. The results from three lid-sutured kittens did not differ significantly from the conclusions drawn from the enucleated animals. The ages at enucleation (lid closure) and the survival periods are indicated graphically in Figure 6 for animals analyzed by immunocytocherristry and in Figure 9 for kittens assayed for GAD activity.

Immunocytochemistry. Animals used for immunocytochemistry were deeply anesthetized with sodium pentobarbital and perfused through the ascending aorta first with $200 \mathrm{ml}$ of $0.9 \% \mathrm{NaCl}$ followed by $0.5 \%$ zinc salicylate (ICN Pharmaceuticals, Inc.) in $10 \%$ formalin at room temperature.
One liter of this fixative was rapidly introduced at a pressure of $100 \mathrm{~mm} \mathrm{Hg}$ followed by a second liter perfused slowly over 20 to $30 \mathrm{~min}$. The $\mathrm{pH}$ of the fixative was an important determinant of the immunocytochemical staining properties of the tissue: we found the staining of GAD terminals (puncta) to be particularly robust at a fixative $\mathrm{pH}$ of 5.0 , while at a fixative $\mathrm{pH}$ of 6.5 , the cell label was enhanced (the zinc salicylate precipitated at $\mathrm{pH} 6.8$ ). Because of our particular interest in puncta, most animals received the lower (unadjusted) $\mathrm{pH}$ fixative.

After the perfusion with $0.5 \%$ zinc salicylate in $10 \%$ formalin, the animals were left undisturbed for $1 \mathrm{hr}$ to allow penetration of the fixative. For animals whose brains were later sectioned on the Vibratome, this was followed by a vascular rinse of 1 liter of cold $10 \%$ formol saline. These brains were removed from the skull and immediately sectioned. For animals whose brains were later sectioned in the cryostat, it was followed by perfusion of 1 liter of cold $10 \%$ sucrose in saline and a second liter of cold $20 \%$ sucrose in saline. These brains were removed from the skull and immersed in 30\% sucrose in saline overnight at $5^{\circ} \mathrm{C}$.

The method used to section the tissue also affected the staining characteristics. The structural integrity of the GAD-positive cells was best preserved in Vibratome sections. However, the increased antibody penetration in the cryostat sections dramatically increased the puncta label (cf. Figs. $1 A$ and $B$ and 2A). Again, because of our particular interest in the puncta distribution, most brains were cut on the cryostat. Curiously, the method used to freeze the brain also affected the immunocytochemistry: brains frozen in $-50^{\circ} \mathrm{C} 2$. methylbutane had virtually no immunoreactivity compared with brains frozen in powdered dry ice. In all cases the cortex was sectioned at 25 to $40 \mu \mathrm{m}$ in approximately the horizontal plane. This is the optimal plane of section to visualize ocular dominance columns in the cat (LeVay et al., 1978).

The sections were collected in $0.5 \mathrm{M}$ Tris buffer, $\mathrm{pH}$ 7.6. All of the subsequent washes and antibody dilutions were in this buffer uniess otherwise indicated. The tissue was processed for immunocytochemistry according to a modification of Sternberger's peroxidase-antiperoxidase (PAP) method (Sternberger, 1979). The sections were first incubated for 1 to $5 \mathrm{~min}$ in $10 \%$ methanol in $3 \% \mathrm{H}_{2} \mathrm{O}_{2}$ to quench the endogenous peroxidases. After six 5 -rrinir washes, the sections were transferred into $10 \%$ normal rabbit serum for $1 \mathrm{hr}$ at room temperature. Next, they were incubated for $48 \mathrm{hr}$ at $5^{\circ} \mathrm{C}$ in GAD antiserum, purified from sheep, at a dilution of 1:1500. This was followed by six 5 -min washes and incubation of $45 \mathrm{~min}$ at room temperature in rabbit anti-goat lgG serum (Sternberger-Meyer) diluted 1:100 (rabbit antigoat $\lg G$ cross-reacts with sheep $\operatorname{lgG}$ ). After six more washes the tissue was incubated for $45 \mathrm{~min}$ at room temperature in goat PAP (Sternberger-Meyer) diluted 1:100. the sections were again thoroughly washed and reacted for $20 \mathrm{~min}$ in a solution containing $0.05 \%$ diaminobenzidene and $0.01 \% \mathrm{H}_{2} \mathrm{O}_{2}$. After this step, the sections were washed in $0.1 \mathrm{~m}$ phosphate-buffered saline, $\mathrm{pH}$ 7.4. In some cases, the tissue was briefly osmicated in $0.01 \% \mathrm{OsO}_{4}$ in phosphate buffer. Finally, the sections were mounted on slides, dehydrated in alcohols, cleared in xylene, and coverslipped. This material was examined on a Leitz Orthoplan microscope using brightfield, interference contrast, and darkfield optics.

To test the possibility that the observed staining resulted from nonimmunologic reactions of the histochemical reagents, the sheep anti-GAD was omitted from the immunocytochemical protocol. In some cases the antiserum was replaced with preimmune sheep plasma. In either case, these procedures abolished all staining of neurons and puncta. The possibility of antibody cross-reactivity cannot be excluded; therefore, the "GAD-like" immunoreactivity reported will be referred to as "GAD" with this reservation clearly in mind.

Cytochrome oxidase histochemistry. In some cases, sections adjacent to those reacted for GAD were stained for cytochrome oxidase according to the method of Wong-Riley (1979). The only modification was that we incubated the sections in the reaction medium containing $0.05 \%$ cytochrome c-type III (Sigma Chemical Co.) for up to $18 \mathrm{hr}$. This was necessary presumably because of the $0.5 \%$ zinc salicylate fixation.

$G A D$ assay. Kittens were deeply anesthetized with sodium pentobarbital and killed by cervical dislocation; then their brains were rapidly removed. A slab in the approximate coronal plane was cut from each brain, just posterior to the pseudosylvian sulcus and immediately anterior to the posterior suprasylvian sulcus (see Fig. 10). This slab was frozen on powdered dry ice and mounted on a cryostat chuck. The tissue was allowed to warm in a cryostat chamber to $-8^{\circ} \mathrm{C}$, at which time the binocular and monocular segments of striate cortex were carefully dissected. The binocular segment was defined operationally as that cortex lying on the medial wall of the postlateral gyrus, between the crown of this gyrus and the splenial sulcus. The operational definition of the monocular segment was that cortex lying on the superior border of the splenial sulcus (see Fig. 10). Tusa et al. (1978) showed that the lateral 50 to $60^{\circ}$ of the contralateral hemifield, which is viewed only by 

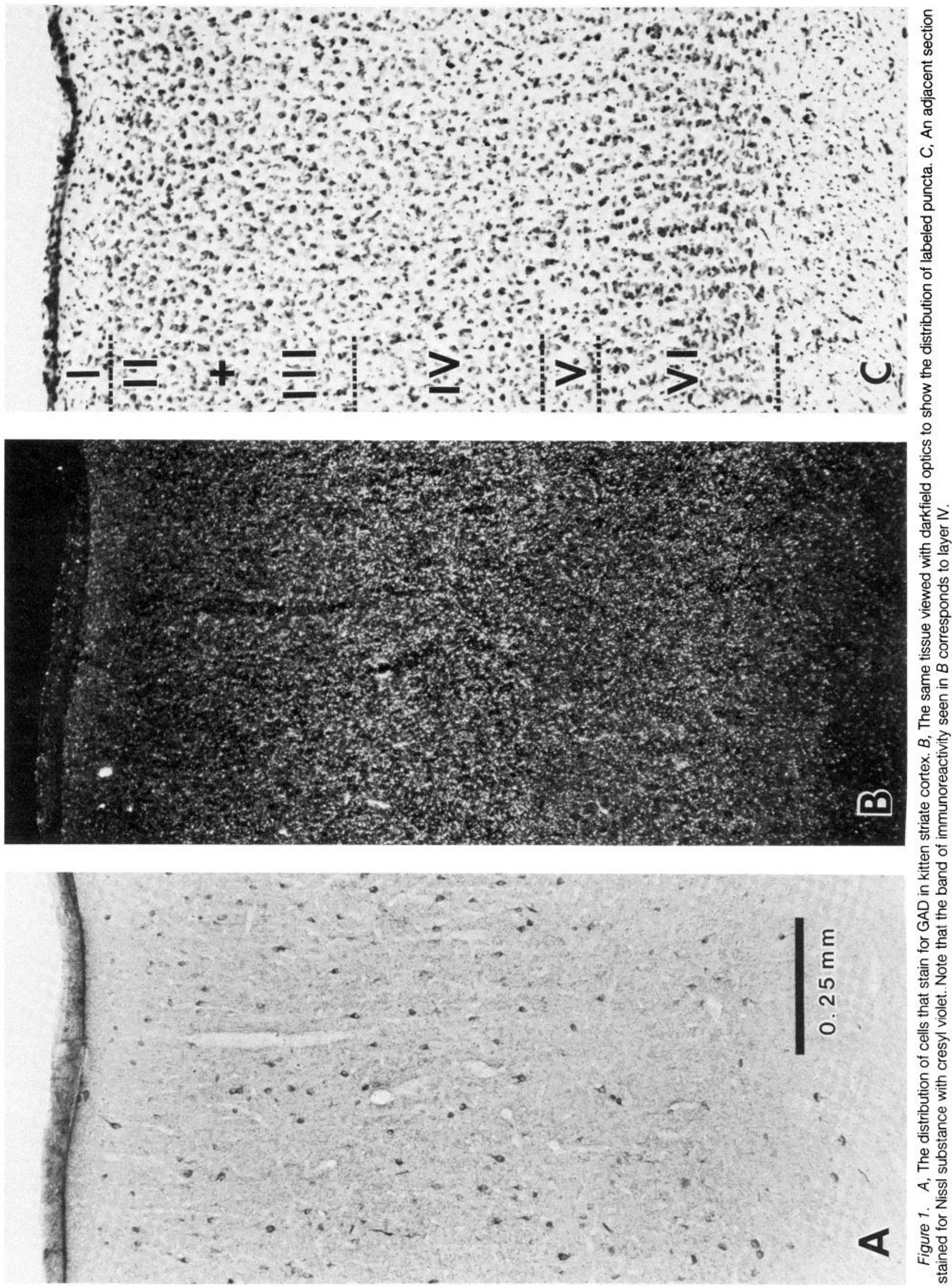


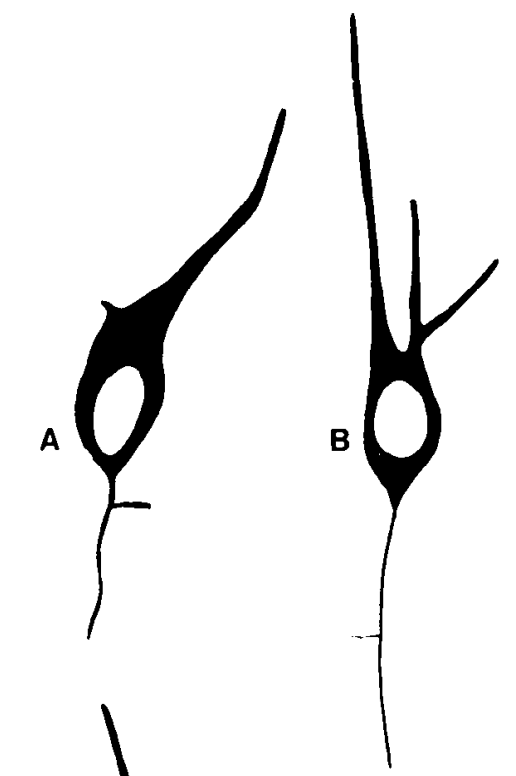

c

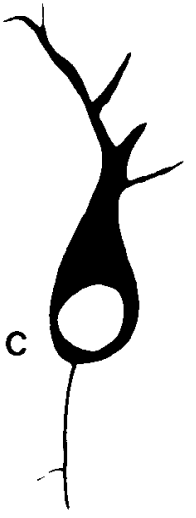

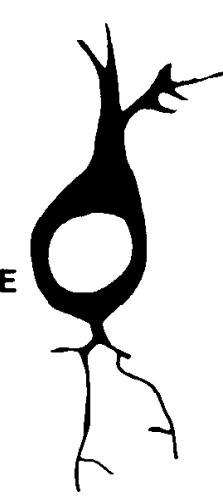

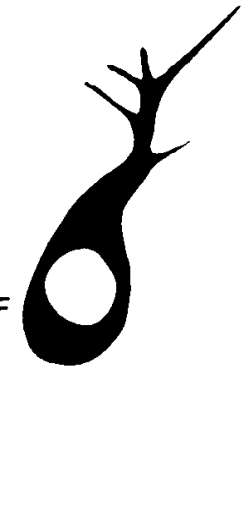

H

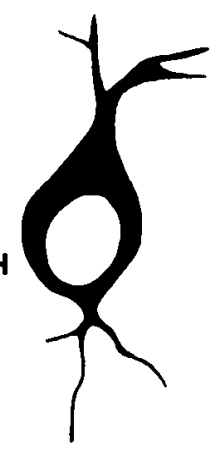

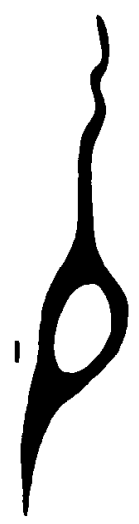
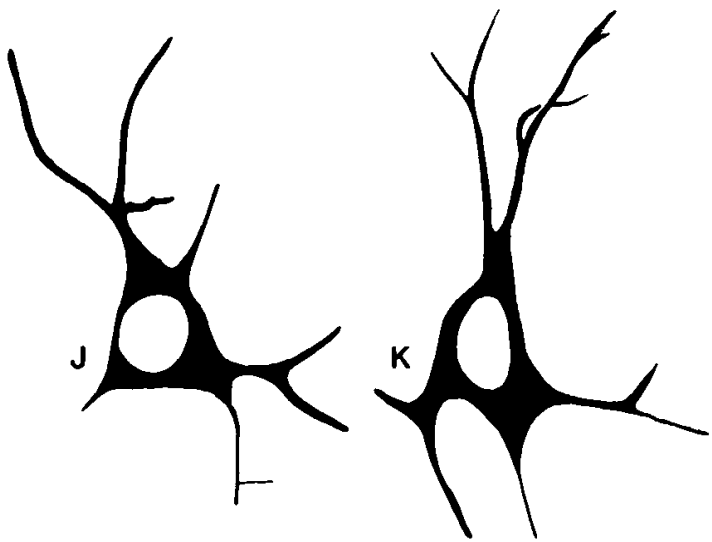

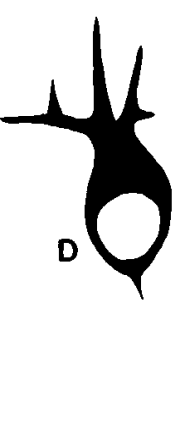

E

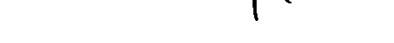

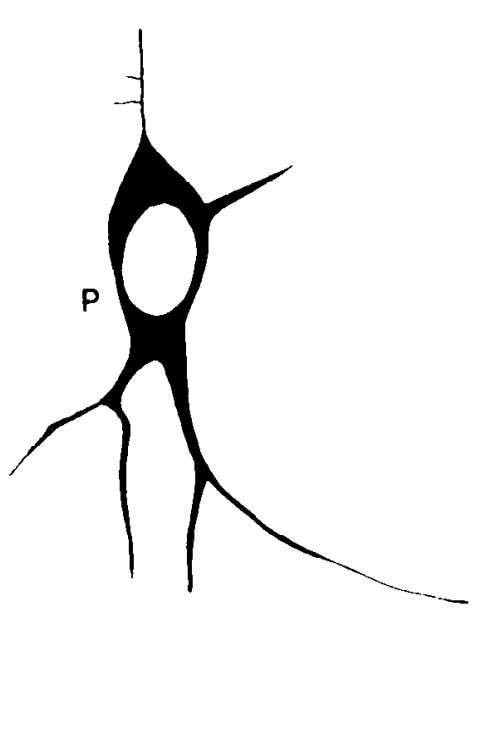

Figure 2. Camera lucida drawings of GAD-immunoreactive neurons in striate cortex. The profile most commonly observed in horizontal sections was tear-drop shaped $(C$ to $H)$. Fusiform cells were also quite common $(A, B$, and $I)$. In some cases axons wcre obscrved lcaving one pole of these cells $(A$ and $B$ ); in other cases dendrites left both poles $(I)$. The other profile seen in this material was stellate shaped with dendrites radiating from the cell body $(J$ to $P$ ). The mean diameter of the cells illustrated $( \pm$ SEM) is $14.62 \pm 0.39 \mu \mathrm{m}$ (uncorrected for tissue shrinkage).

the contralateral retina (Sprague and Meikle, 1965; Sanderson, 1971), is represented in this region of striate cortex. The tissue samples were stored overnight at $-70^{\circ} \mathrm{C}$. Pilot studies indicated that neither the type of anesthesia given to the kittens prior to sacrifice nor the freezing of the tissue appreciably affected the subsequent GAD assay.
The GAD assay was a modification of the isotopic assay described by MacDonnell and Greengard (1975). The tissue was homogenized in 40 vol of $100 \mathrm{~mm}$ potassium phosphate, $\mathrm{pH} 6.5$, containing $0.25 \%$ Triton $\mathrm{X}-100$ to solubilize the enzyme. Three $2.5 \mathrm{mg}$ aliquots of each tissue sample were incubated for $30 \mathrm{~min}$ at $37^{\circ} \mathrm{C}$ in the presence of $100 \mathrm{~mm}$ potassium phosphate 


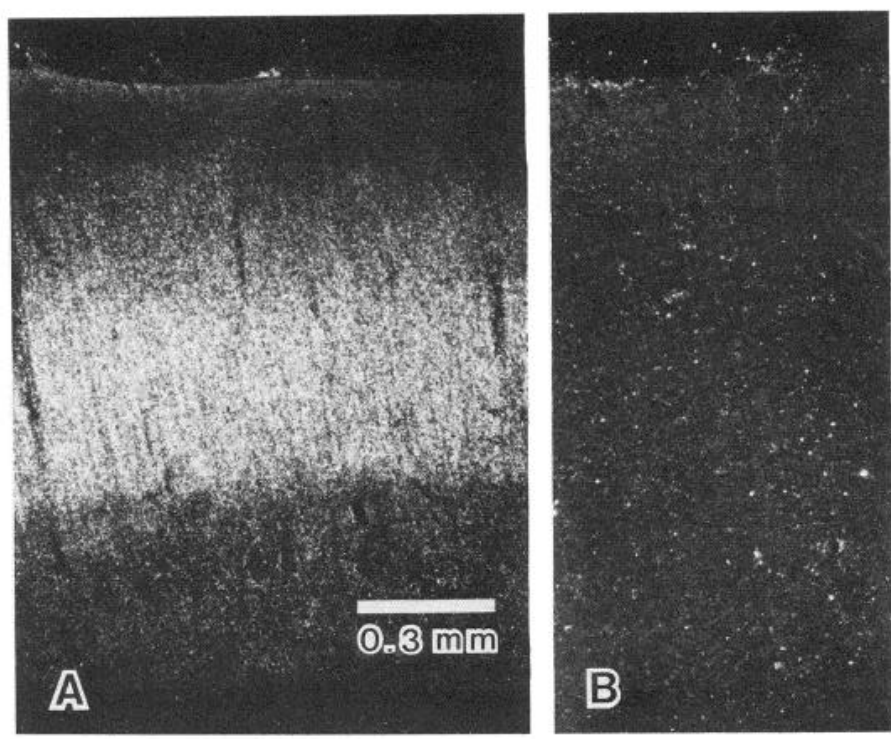

Figure 3. A, Darkfield photomicrograph of striate cortex reacted for GAD immunocytochemistry. In this case, puncta label was optimized by perfusing the tissue with a low pH fixative and by sectioning the tissue in a cryostat (see "Materials and Methods"). Particularly note the dense band of immunoreactivity in layer IV. B, An adjacent section reacted for immunocytochemistry as above, except the anti-GAD was omitted. All immunoreactivity was abolished in this control tissue.

$(\mathrm{pH} 6.5), 0.1 \%$ Triton $\mathrm{X}-100,24 \mathrm{~mm}{ }^{14} \mathrm{C}$-labeled glutamic acid, and $0.1 \mathrm{~mm}$ pyridoxyl phosphate in a final volume of $0.3 \mathrm{ml}$. The incubation was terminated by the addition of $1 \mathrm{ml}$ of $4 \%$ perchloric acid and the ${ }^{14} \mathrm{CO}_{2}$ was trapped as described by Patrick and Rendel (1980). Under these conditions, cat cerebral cortex enzyme activity was completely inhibited by the addition of $1 \mathrm{~mm}$ amino-oxyacetic acid, indicating that decarboxylation of glutamic acid was in fact the source of labeled ${ }^{14} \mathrm{CO}_{2} \cdot{ }^{14} \mathrm{CO}_{2}$ production was linear with respect to time for $30 \mathrm{~min}$ and with respect to tissue for at least $5 \mathrm{mg}$. Tissue to blank (reagents minus tissue) ratios were approxiamtely 10:1. In most cases, the tissue samples were also assayed for protein content by the protein-dye binding method of Bradford (1976).

Biochemical statistical methods. The Student's $t$ test was used to determine the significance of a difference between two sample means. A $p$ value of less than 0.05 was considered significant (Welkowitz et al., 1971). If samples did not differ significantly, the analysis of power was used to estimate the probability of a type II error (the probability of falsely accepting the null hypothesis). For the analysis, the population standard deviation was estimated from the lower of the two standard deviations from the experimental and control groups. In the comparison of binocular segments, the segment from each hemisphere was considered independently.

\section{Results}

Localization of GAD in normal kitten striate cortex. GAD immunoreactivity in kitten striate cortex was found primarily in two compartments: cell bodies and axon terminals (puncta). Stained axons and dendrites were only rarely encountered. The distribution of labeled cell bodies is illustrated in Figure 1. GAD-positive cells were found evenly distributed in layers II to VI. In addition, occasional immunoreactive cells were observed in layer I. Labeled neurons displayed considerable morphological diversity (Fig. 2). The cells ranged from fusiform to stellate in shape with no apparent laminar bias toward any one category. The cell diameters, uncorrected for tissue shrinkage, ranged from 12 to $18 \mu \mathrm{m}$. Pyramidal cells were never stained.

Labeled puncta were best seen at low power using darkfield optics (Fig. 1B). In contrast to the distribution of stained cell bodies, the immunoreactivity associated with axon terminals appeared to be laminated, with a distinct band in layer IV. This label was enhanced remarkably in tissue that was cut in the cryostat (Fig. 3). Although this would seem to indicate that layer IV has a higher density of GAD-positive axon terminals, a close examination of tissue cut on the Vibratome revealed that the band in layer IV probably results from the puncta being larger, but not necessarily more numerous (Fig. 4). It is safe to say, however, that layer IV of kitten striate cortex contains more immunoreactive GAD than the other layers. Outside of layer IV, the puncta appeared relatively uniform in size and evenly distributed. One exception was the inner half of layer I which displayed little immunoreactivity. However, at high magnifications, even this region was found to contain a population of small, lightly stained puncta.

The puncta formed characteristic patterns in striate cortex. They were frequently observed surrounding unlabeled cell bodies. This was true for both stellate and pyramidal cell types. Puncta were also seen in high density around GAD-positive perikarya.

Distribution of GAD in striate cortex after MD. Immunocytochemistry is not useful for making quantitative statements about differences between animals. The staining depends on too many variables that are difficult to control adequately. However, within the same animal, it should be possible to detect regional changes in the tissue distribution of immunoreactive GAD. We therefore processed a number of animals for immunocytochemistry that had been unilaterally enucleated during or before the critical period (defined by the experiments of Hubel and Wiesel (1970) as 3 weeks to 3 months of age). We focused our attention primarily on the possibility of changes in the band of GAD immunoreactivity in layer IV. The animals used in this study are listed in Figure 5.

Kittens in our first series were enucleated on day 35 and survived for 5 weeks before being sacrificed for immunocytochemistry (animals K201, K202, and K203). In no case could we see changes in GAD immunoreactivity that could be attributed unequivocally to the altered rearing conditions. In particular, the layer IV puncta formed an uninterrupted band that contained no hint of regular periodic variations in staining density in any dimension. We next examined the possibility of transient changes in GAD in K205, who survived enucleation on day 35 for only 10 days. Again, no changes were observed in the distribution of GAD puncta.

In animals K201 to K205 the enucleations were performed on day 35,2 weeks into the critical period. We wondered whether the postulated GABAergic response was dependent on deprivation during these 2 weeks. We tested this idea in animals K206 to K209, who were enucleated on day 21. As in the previous cases, no changes in GAD were detected.

In another series of kittens (K212, K213, K215, and K237) the animals were allowed to survive for periods in excess of 2 months. The ages at enucleation ranged from day 7 to day 35 (Fig. 5). In addition to GAD immunocytochemistry, we reacted tissue from K213 and K215 for cytochrome oxidase. An example of the results obtained from these kittens is illustrated in Figure 6 . The cortical cytochrome oxidase pattern is normally characterized by a dense band in layer IV. In enucleated animals this band is interrupted by stain-sparse zones that have been shown by Wong-Riley (1979) to correspond to the enucleated eye ocular dominance columns (Fig. $6 A$ ). However, adjacent sections reacted for GAD immunocytochemistry reveal no corresponding periodic fluctuations in the density of layer IV puncta (Fig. 6B). Again, the distribution of GAD immunoreactive elements in striate cortex appeared to be unchanged by early enucleation, even after a survival period in this case of over 100 days.

Animals in the final series used for GAD immunocytochemistry were monocularly deprived by lid closure instead of eye removal (Fig. 5, asterisks). Two of these kittens survived well into adulthood (K246 and K249). As was the case for the enucleated animals, the MD had no consistent effect on either the regional or laminar distribution of GAD in striate cortex.

Although our attention was directed toward the distribution of GAD in striate cortex, particularly in layer IV, we did react sections through the lateral geniculate nucleus for both GAD immunocytochemistry and cytochrome oxidase histochemistry. The denervated laminae of the geniculate showed marked cell atrophy 

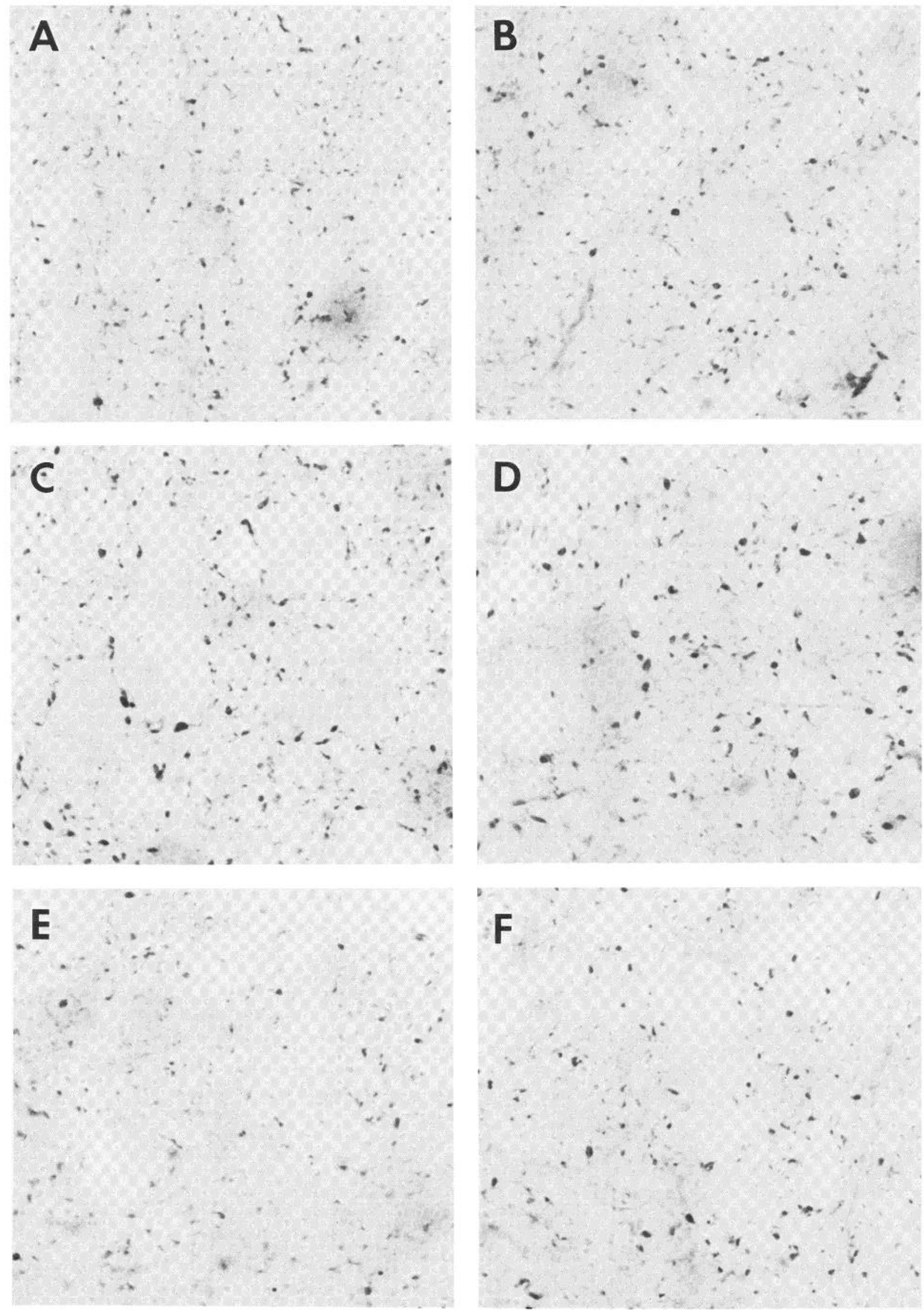

Figure 4. High magnification survey of puncta size and number in Vibratome-sectioned material. Photomicrographs are from layers $\|+111(A)$, lower layer III $(B)$, layer IV $(C$ and $D)$, layer $V(E)$, and layer VI $(F)$. Particularly note the large size of layer IV puncta $(C$ and $D)$. Magnification $\times 1160$. 


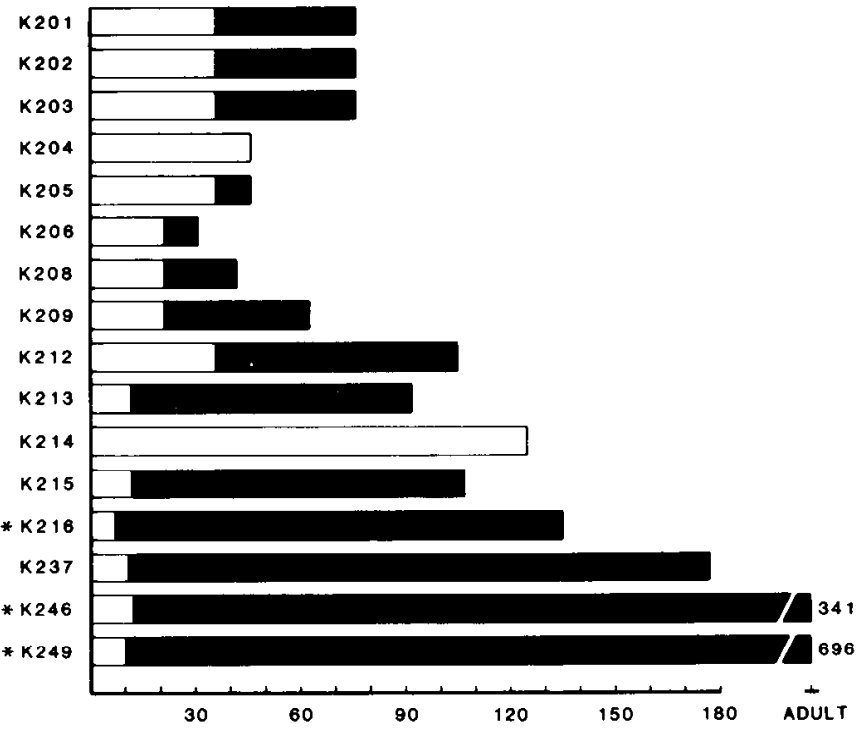

Figure 5. A list of animals used for GAD immunocytochemistry. The bar length, measured in days, represents the age of each kitten at the time of sacrificc. The open bar represents time with both eyes intact, and the solid bar represents time after eye removal (in the case of animals marked with an asterisk, the solid bar represents time after eyelid closure

(Fig. 7, top) and a profound loss of cytochrome oxidase activity (Fig 7, middle). However, even the denervated geniculate laminae displayed nearly normal GAD immunoreactivity (Fig. 7, bottom) Changes that are induced in GABAergic geniculate neurons by enucleation warrant a more detailed analysis.

The effects of enucleation on cortical GAD activity. The striate cortex of enucleated kittens was assayed for GAD enzyme activity as a quantitative estimate of changes in GAD puncta density. We were particularly interested in two possibilities: first, that the monocular segment contralateral to the enucleated eye might have elevated GAD activity as compared with the ipsilateral segment in the same animal, and second, that the monocular segments of enucleated kittens might have elevated GAD activity as compared with age-matched control kittens. The kittens used in this study are listed in Figure 8. In all cases, the left eye was removed during the second week of life. At the time of sacrifice, the tissues were dissected as illustrated in Figure 9 (see "Materials and Methods" for details).

A comparison of the GAD activity in the right and left monocular segments of enucleated kittens is shown in Table I. Each value is the mean $( \pm S E M)$ of three determinations of enzyme activity. The right monocular segment (MSR) was always contralateral to the cnucleated eye. The left monocular segment (MSL) served as sameanimal control tissue. Considering only those kittens aged 131 days or less (for comparison with the binocular segment data), we found the MSR activity to be $8.41 \pm 0.32 \mu \mathrm{mol}$ of $\mathrm{GABA} / \mathrm{hr}-\mathrm{gm}$ and the MSL activity to be $8.30 \pm 0.54 \mu \mathrm{mol}$ of GABA/hr-gm. Within this group, only K219 showed a significant interhemispheric difference, with MSR activity being elevated over MSL activity by $24 \%$. However, the fact that no other animals in this age range displayed any significant change, including K222 (only 1 week older), means that the difference in K219 was probably artifactual. Besides these seven kittens, four more enucleated animals between 154 and 166 days of age were assayed. In this group, only K235 had an MSR value that differed significantly from that for MSL. In this case MSR activity was $32 \%$ lower than that of MSL. Again, however, other animals in this group failed to show a similar difference, including an agematched littermate (K234). Condensing the data from all of the kittens assayed yields a value for experimental tissue (MSR) of $9.50 \pm 0.63$ $\mu \mathrm{mol}$ of GABA/hr-gm compared to $9.42 \pm 0.73 \mu \mathrm{mol}$ of GABA/hr$\mathrm{gm}$ for the control tissue (MSL). This difference is not significant. These data are represented graphically in Figure 10A.
In Table II, GAD activity in the binocular segments of six enucleated kittens is compared to the activity in six age-matched, littermate control kittens. The kittens were assayed at a number of ages ranging from 39 to 131 days. Only at 114 days did the experimental values differ significantly from control: right binocular segment (BSR) activity in K219 was $17 \%$ less than BSR activity in K220. As was the case with the monocular segments, this difference is likely to be spurious since the kittens at 82 days (K223 and K224) and at 121 days (K222 and K223) displayed no significant changes. The mean GAD activity ( \pm SEM) of the binocular segments of all six enucleated kittens was $11.03 \pm 0.67 \mu \mathrm{mol}$ of GABA/hr-gm compared with 11.10 $\pm 0.81 \mu \mathrm{mol}$ of GABA/hr-gm in the binocular segments of the control animals. These data are represented graphically in Figure $10 B$.

Because we were particularly interested in the actual amount of enzyme, the assays were run at a substrate concentration near saturation (24 mM glutamate). However, GAD kinetic determinations were made in the monocular segments of several kittens. We found the apparent $K_{m}$ to be approximately $1.0 \mathrm{~mm}$ for control tissues. Experimental tissue enzyme kinetics were not found to differ significantly.

\section{Discussion}

Distribution of GAD in kitten striate cortex. The pattern of GAD immunoreactivity found in kitten striate cortex agrees well with the description of Fitzpatrick et al. (1983b) for adult cat area 17; that is, a relatively uniform distribution of labeled cell bodies in layers $\|$ through VI, occasional immunoreactive neurons in layer I, and laminated immunoreactivity associated with puncta, with a distinct band in layer IV. That this distribution of GAD was seen even in the youngest kittens examined suggests that GABAergic circuitry in striate cortex is already quite mature at 1 month of age. The relatively high level of GAD activity in 5-week-old kittens is consistent with this suggestion.

There was considerable diversity in the morphology of labeled neurons in layers II to VI. Because the antisera only penetrate a few micrometers into the tissue, and because the appearance of stained cells depends on the plane of section, no attempt has been made to systematically classify the immunoreactive neurons. However, it is clear that all of the GAD positive cells in kitten striate cortex fall into the broad category of nonpyramidal neurons with aspinous or sparsely spinous dendrites. Golgi staining (O'Leary, 1941; Lund et al., 1979; Peters and Regidor, 1981) and, recently, intracellular filling with horseradish peroxidase (HRP) (Gilbert and Wiesel, 1979; Freund et al., 1983; Martin et al., 1983) have revealed the morphological heterogeneity of cells in this category. O'Leary (1941) split this group into two divisions: those cells with locally arborizing axons, usually confined within a single layer, and those cells with widely ramitying axons. Among the cells in the first group are small multipolar cells (Peters and Regidor, 1981) and "chandelier" cells that Freund et al. (1983) recently showed to form synapses on the initial segments of pyramidal cell axons. The latter group, nonpyramidal cells with widely arborizing axons, may be further divided into those neurons with radially directed axonal arbors and those with horizontally directed axonal arbors (Peters and Regidor, 1981). The most significant population of horizontally projecting smooth stellates is the "basket cell" whose terminals have been found to form pericellular baskets around the somas of pyramidal cells. Attempts have been made to further subdivide these classes according to their afferent connectivity (Hamos et al., 1983). It is therefore quite clear that all GADpositive cells in striate cortex are not equivalent but, rather, are divisible into a number of morphologically distinct classes. It is interesting to note that even cells of similar morphology can have diverse physiological properties (Martin et al., 1983). Likewise, cells with similar physiology may be morphologically quite distinct (Gilbert and Wiesel, 1979).

GAD-positive cells in layer I were first described by Ribak (1978) in the ral. They have since been found in the monkey (Hendrickson et al., 1981; Fitzpatrick et al., 1983b), the turtle (Smith and Ebner, 

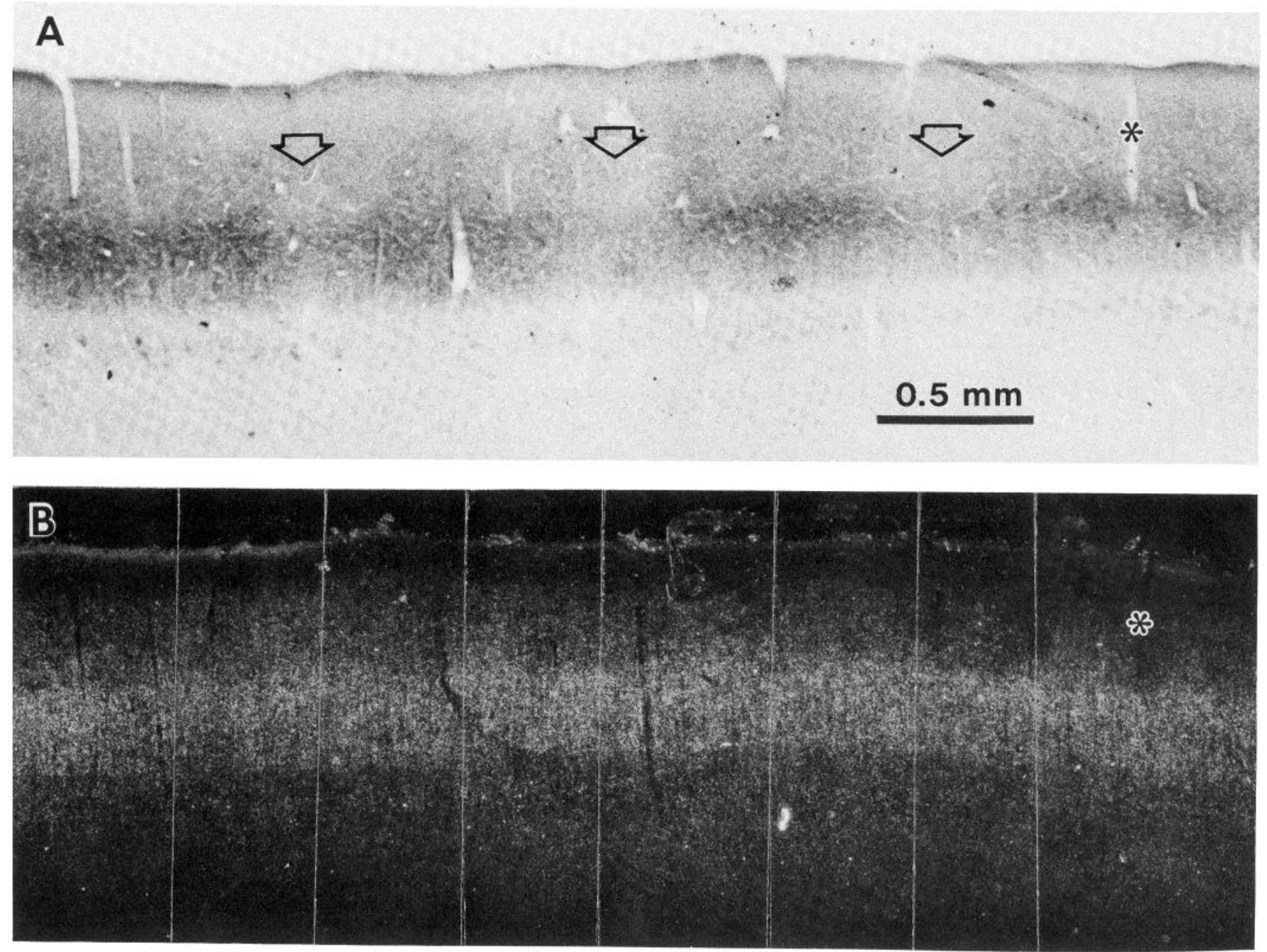

Figure 6. A, The cytochrome oxidase staining pattern in the striate cortex of an enucleated kitten (K215). The stain-poor zones in layer IV (arrows) correspond to the enucleated eye ocular dominance columns. B, Darkfield montage of an adjacent section reacted for GAD immunocytochemistry. The asterisk marks the same blood vessel as in A. Note that GAD puncta form a continuous band in layer IV with no periodic variations in staining density.

1980), the mouse (Smith et al., 1983) and the cat (Fitzpatrick et al., 1983b; Freund et al., 1983) and are likely to be a feature shared by all mammals. The GAD-immunoreactive neurons in upper layer I of kitten striate cortex are characterized by horizontally oriented dendrites and resemble the horizontal cells of Retzius-Cajal. Golgi impregnation of these neurons reveals an axonal arbor that is largely restricted to layer I (Peters and Regidor, 1981). In contrast, the GADpositive cells in lower layer I appear to be oriented radially with axons that can be followed into layers II and III (e.g., Fig. $2 A$ ). Inputs to layer I have traditionally been thought of as only "modulatory" because of their termination on the distal dendrites of target neurons. However, activation of the GAD-positive cells in lower layer I could have a precise and powerful effect on their targets in deeper layers.

The patterns of labeled puncta seen in kitten visual cortex are similar to those found in adult cat area 17 (Fitzpatrick et al., 1983b; Freund et al 1983) as well as in the neocortex of other species (Ribak, 1978; Hendrickson et al., 1981; Smith et al., 1983). The common feature is a close association of puncta with the cell bodies of unlabeled pyramidal and stellate cells as well as with the perikarya of immunoreactive cells. Darkfield illumination reveals a distinct lamination of the immunoreactivity associated with puncta, with a dense band occurring in layer IV. We agree with the suggestion of Fitzpatrick et al. (1983b) that the layer IV band is mainly due to larger puncta in this layer. Consistent with this interpretation is the finding that the numerical density of synapses with an FS morphology is not higher in layer IV than in the other layers (Beaulieu and Colonnier, 1983b). It is not clear why freezing the tissue enhances the immu. noreactivity of this layer so much, although it must certainly relate in part to increased penetration of the immunological reagents.

The regions of increased puncta size seem to correspond to zones of thalamic termination (Fitzpatrick et al., 1983a, b) and to zones of high cytochrome oxidase activity (Hendrickson et al., 1981; Fitzpatrick et al., 1983a). The suggestion has recently been made that a small fraction of lateral geniculate terminals may release GABA in cat striate cortex (Einstein et al., 1983). We cannot absolutely exclude the possibility that some layer IV puncta arise from the lateral geniculate nucleus, but partial undercutting of striate cortex in one kitten did not result in any detectable reduction in GAD immunoreactivity. This fits with the observation that no GAD-positive neurons in the lateral geniculate nucleus contain retrograde label after HRP injections into cat striate cortex (Fitzpatrick et al., 1982). It thus appears that the balance of available evidence still favors the hypothesis that the vast majority of GAD-positive axon terminals in striate cortex arise from cortical interneurons. Why cytochrome oxidase and GAD correspond so closely is unknown, but apparently these staining patterns can be dissociated in kittens by monocular enucleation (Fig. 6).

We consistently found that the GAD activity of the binocular segment was higher (approximately 25\%) than in the monocular segment. Immunocytochemical preparations did not reveal any re- 

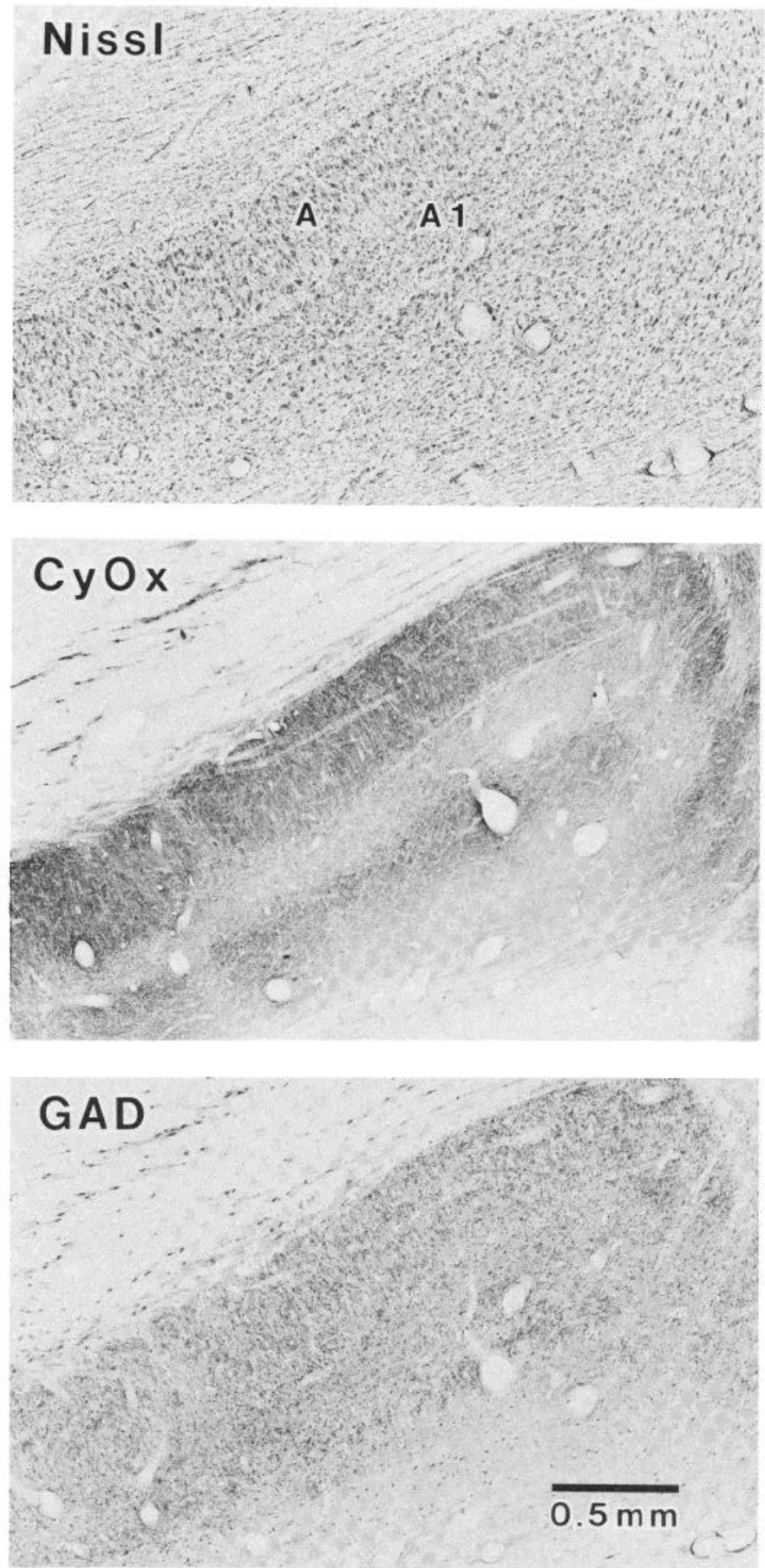

Figure 7. The lateral geniculate nucleus of an enucleated kitten (K215). Top, Nissl stain of the nucleus ipsilateral to the enucleated eye. Note the atrophy of cells in lamina A1. Middle, An adjacent section reacted for cytochrome oxidase $(\mathrm{CyOx})$. The stain is severely depleted in lamina A1. Bottom, An adjacent section reacted for GAD. There is little apparent change in the GAD immunoreactivity of the denervated lamina.

markable differences in the density of GAD-positive elements, although the cortex on the superior lip of the splenial sulcus (monocular segment) always appeared thinner than the cortex on the medial wall of the lateral gyrus (binocular segment). This observation is consistent with the careful stereological studies of the monocular and binocular cortices in the cat by Beaulieu and Colonnier (1983a, b). They find that, although the cortex of the monocular segment is significantly thinner (about 24\%), the numerical densities (Nv) of neurons and synapses (including the FS type) in the two segments

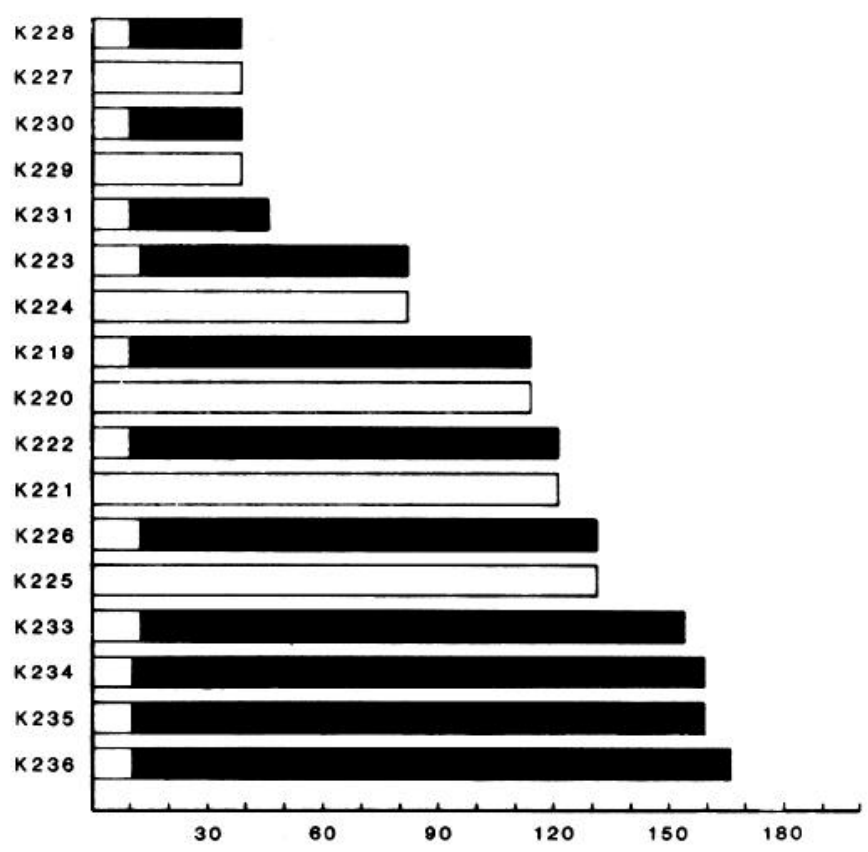

Figure 8. The animals used for GAD biochemistry, listed in order of increasing age (in days). See Figure 5 legend for conventions.
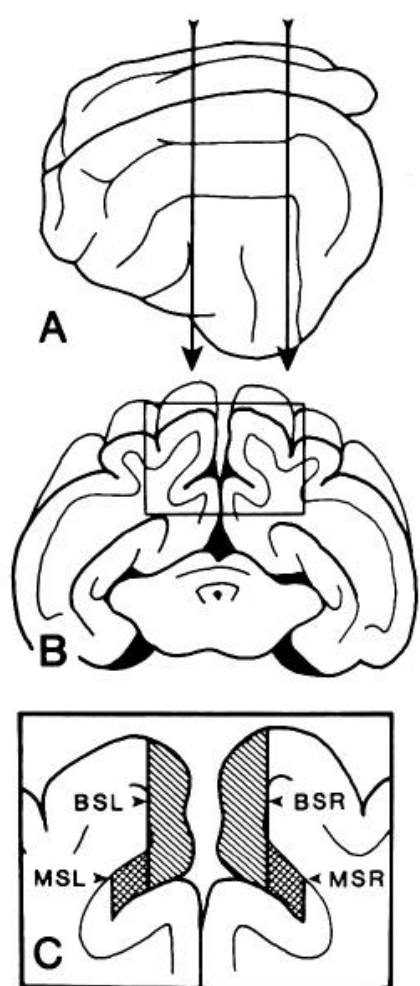

Figure 9. The dissection of striate cortex for the GAD assay. A, A slab of freshly dissected tissue was taken just posterior to the pseudosylvian sulcus, and just anterior to the posterior suprasylvian sulcus. $B$, This slab was frozen in powdered dry ice, mounted on a cryostat chuck, and allowed to warm to $-8^{\circ} \mathrm{C}$. $\mathrm{C}$, In a cryostat chamber, the binocular and monocular segments were dissected as shown. BSL, left binocular segment; $B S R$, right binocular segment; MSL, left monocular segment; MSR, right monocular segment. 
TABLE I

Monocular segment GAD activity in enucleated kittens

The activity of glutamic acid decarboxylase in the monocular segments of enucleated kittens. Animals are listed in order of increasing age, indicated on the left. MSL, the left monocular segment, was always ipsilateral to the enucleated eye and thus served as control tissue. MSR, the right monocular segment, was contralateral to the enucleated eye and served as experimental tissue. The GAD activity for each tissue is the mean $( \pm S E M)$ of three determinations (except for K233 MSL which is the mean of two determinations). Percentage of CTL (control) is MSR activity as a percentage of MSL activity. These data are recast in Figure $11 A$.

\begin{tabular}{|c|c|c|c|c|}
\hline Age & Animal & MSL & MSR & Percentage of CTL \\
\hline days & \multicolumn{4}{|c|}{$\mu \mathrm{mol}$ of GABA/hr-gm of tissue } \\
\hline 39 & K228 & $7.14 \pm 0.70$ & $8.83 \pm 1.34$ & +19 \\
\hline 39 & $\mathrm{~K} 230$ & $9.76 \pm 0.90$ & $8.70 \pm 0.56$ & -11 \\
\hline 46 & $\mathrm{~K} 231$ & $10.43 \pm 0.88$ & $9.19 \pm 0.43$ & -12 \\
\hline 82 & K223 & $8.12 \pm 0.48$ & $7.00 \pm 0.31$ & $-14^{a}$ \\
\hline 114 & K219 & $6.27 \pm 0.43$ & $8.29 \pm 0.18$ & +24 \\
\hline 121 & K222 & $8.37 \pm 0.10$ & $7.54 \pm 0.15$ & -10 \\
\hline 131 & $\mathrm{~K} 226$ & $8.03 \pm 0.93$ & $9.30 \pm 0.66$ & +14 \\
\hline 154 & K233 & 7.93 & $11.69 \pm 1.33$ & +32 \\
\hline 159 & $K 234$ & $13.58 \pm 0.40$ & $14.62 \pm 0.06$ & +7 \\
\hline 159 & K235 & $13.60 \pm 0.25$ & $9.27 \pm 0.18$ & $-32^{\mathrm{a}}$ \\
\hline \multirow[t]{2}{*}{166} & K236 & $10.35 \pm 1.30$ & $10.11 \pm 1.15$ & -2 \\
\hline & Mean: & $9.42 \pm 0.73$ & $9.50 \pm 0.63$ & +1 \\
\hline
\end{tabular}

${ }^{a}$ Significantly different at $p<0.05$.

are nol different. In other words, there are approximately $25 \%$ fewer neurons and synapses under $1 \mathrm{~mm}^{2}$ of pia in the monocular segment than under the same surface area in binocular cortex. It thus appears that the volumes of tissue dissected for the GAD assay from the thinner monocular segments contained more white matter (and thus less enzyme) than did equivalent volumes from binocular cortex.

The role of GABAergic circuitry in the cortical response to $M D$. Most neurons in cat striate cortex may be activated by stimulation of either eye and hence are binocular. However, MD of young kittens alters cortical physiology such that most neurons become responsive only to the open eye (Hubel and Wiesel, 1970). This ocular dominance shift is accounted for in part by an expansion of the gericulate terminal zone subserving the open eye and a decrease in the layer IV territory normally innervated by deprived eye geniculate afferents. This explains why only $20 \%$ of layer N neurons are responsive to the deprived eye after MD (Shatz and Stryker, 1978). However, the fraction of cells outside of layer IV that remain responsive to deprived eye stimulation is considerably smaller, suggesting that intracortical connections are also affected by deprivation. Furthermore, an ocular dominance shift is not always accompanied by an anatomical redistribution of geniculate afferents (Presson and Gordon, 1982). These lines of evidence have directed recent attention to possible mechanisms of intracortical plasticity.

The experiments of Kratz et al. (1976) first suggested the possibility of an inhibitory mechanism for the ocular dominance shift. They found in monocularly deprived kittens that enucleation of the open eye restored responsiveness to the deprived eye in many cortical units. This effect was age related, being most dramatic in kittens between 4 and 5 weeks old, but still persisting into adulthood (Spear et al., 1980). Although the exact mechanism remained uncertain, it nonetheless appeared that deprived eye responses were somehow being suppressed by tonic open eye activity. GABAergic circuitry was implicated in this suppression when Duffy et al. (1976) found that bicuculline would also restore some cortical responsiveness to the deprived eye. These data are consistent with the hypothesis that one mechanism of visual cortical plasticity involves sprouting of

\section{GAD ACTIVITY IN ENUCLEATED KITTENS}

\section{A. MONOCULAR SEGMENT}

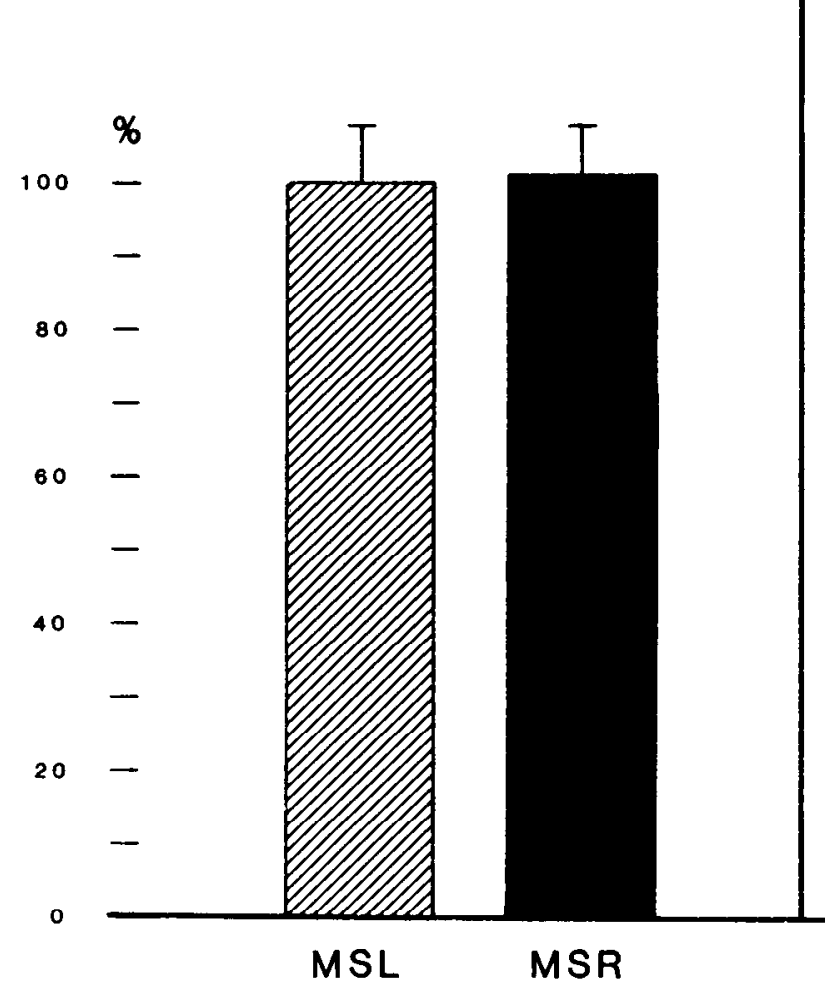

\section{B. BINOCULAR SEGMENT}

Figure 10. Results of the GAD assay in enucleated kittens. A, A comparison of the activity in the left (control) monocular segments (MSL) with the right (experimental) monocular segments (MSR). MSR activity is $101 \%( \pm 7 \%)$ of MSL. B, A comparison of the activity in the binocular segments of control (CTL) and enucleated (EXP) kittens. The experimental tissue activity is $99 \%( \pm 6 \%)$ of control. 
TABLE \|

Binocular segment GAD activity in enucleated kittens

The GAD activity for the binocular segments of six enucleated and six age-matched littermate controls. Each value is the mean ( $($ SEM) of three determinations. These data are recast in the histograms of Figure $11 B$.

\begin{tabular}{|c|c|c|c|}
\hline Age & Animal & BSL & BSR \\
\hline days & & \multicolumn{2}{|c|}{$\mu \mathrm{mol}$ of $\mathrm{GABA} / \mathrm{hr}-\mathrm{gm}$} \\
\hline & \multicolumn{3}{|l|}{ Enucleated } \\
\hline 39 & K228 & $9.07 \pm 0.1$ & $9.62 \pm 0.76$ \\
\hline 39 & $K 230$ & $11.36 \pm 1.54$ & $13.59 \pm 2.16$ \\
\hline 82 & $k 223$ & $12.15 \pm 1.23$ & $14.44 \pm 3.05$ \\
\hline 114 & $\mathrm{~K} 219$ & $8.09 \pm 0.62$ & $8.26 \pm 0.35^{\circ}$ \\
\hline 121 & $\mathrm{~K} 222$ & $9.31 \pm 0.89$ & $10.17 \pm 0.33$ \\
\hline \multirow[t]{3}{*}{131} & $\mathrm{~K} 226$ & $14.78 \pm 1.07$ & $11.51 \pm 0.89$ \\
\hline & & \multicolumn{2}{|l|}{ Mean: $11.03 \pm 0.67$} \\
\hline & \multicolumn{3}{|l|}{ Control } \\
\hline 39 & K227 & $8.46 \pm 0.52$ & $7.86 \pm 0.65$ \\
\hline 39 & $K 229$ & $11.54 \pm 0.38$ & $10.15 \pm 1.31$ \\
\hline 82 & $\mathrm{~K} 224$ & $14.73 \pm 2.14$ & $11.00 \pm 2.02$ \\
\hline 114 & $K 220$ & & $9.93 \pm 0.07$ \\
\hline 121 & K221 & $10.09 \pm 0.39$ & $9.41 \pm 0.71$ \\
\hline \multirow[t]{2}{*}{131} & K225 & $16.96 \pm 0.48$ & $11.98 \pm 0.39$ \\
\hline & \multicolumn{3}{|c|}{ Mean: $11.10 \pm 0.81$} \\
\hline
\end{tabular}

${ }^{a}$ Significantly different from age-matched control, $p<0.05$.

GABAergic neurons in ocular dominance column domains that are deprived of a normal input. Implications of this hypothesis are illustrated in Figure 11.

The hypothetical synaptic input to a cortical neuron is plotted as a function of stimulus orientation in Figure $11 \mathrm{~A}$. In this illustration the excitatory inputs are broadly tuned (Fig. 11A, solid line) and, for convenience, the inhibitory inputs are untuned for stimulus orientation (Fig. 11A, dashed line). ${ }^{5}$ The output of such a cell, as measured

${ }^{5}$ We stress that the shapes of these luning curves have been chosen for ilustrative purposes only and are not meant to be interpreted literally. with an extracellular recording electrode, is simply estimated as the difference between excitatory and inhibitory input at each orientation (Fig. 11B). If MD increased the inhibitory GABAergic input to a cell in the deprived eye ocular dominance domain (Fig. 11C, arrow), then the cellular response to deprived eye stimulation would be abolished (Fig. 11D), even though the cell receives a normal complement of excitatory inputs. However, when the inhibitory inputs are antagonized by bicuculline (Fig. 11E, arrows), the excitatory inputs are "unmasked" and the cell's response to the deprived eye is restored (Fig. 11F).

In the present study we investigated the possible structural basis for this hypothesis. In the immunocytochemical experiments, attention was focused on layer IV for two reasons. First, changes in GAD after denervation in turtle visual cortex (Smith and Ebner, 1980) and in rat hippocampus (Goldowitz et al., 1982) were restricted in each case to the denervated sublamina. Second, iontophoretic bicuculline most clearly restores deprived eye responsiveness to simple cells in monocularly deprived kittens (Burchfiel and Duffy, 1981). Virtually all neurons in layer IV have this type of receptive field. Finally, the dense band of GAD immunoreactivity in layer IV made it particularly amenable to detect changes in puncta density.

We found no evidence for a change in the distribution of GADpositive puncta in kittens that were either unilaterally enucleated or lid sutured. The band of layer IV puncta remained uniform even though the periods of MD examined would all be sufficient to cause a physiological ocular dominance shift in striate cortex (Hubel and Wiesel, 1970; Olson and Freeman, 1975). GAD immunoreactivity was unchanged even under conditions that did produce alterations in the level of the metabolic enzyme, cytochrome oxidase. Although these experiments apparently ruled out relative changes in GAD puncta density, they did not address the possibility of absolute changes in the density of puncta in kitten visual cortex after enucleation. Therefore, as a quantitative measure of GAD, we assayed enzyme activity in homogenates of striate cortex from enucleated and control kittens.

The results of the GAD assay show no consistently significant difference between either the binocular segments of enucleated and control kittens or the monocular segments of enucleated animals,

\section{NORMAL INPUT}

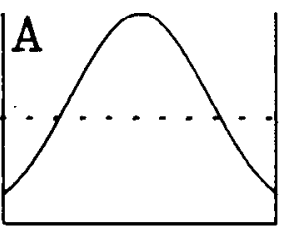

SYNAPTIC INPUT

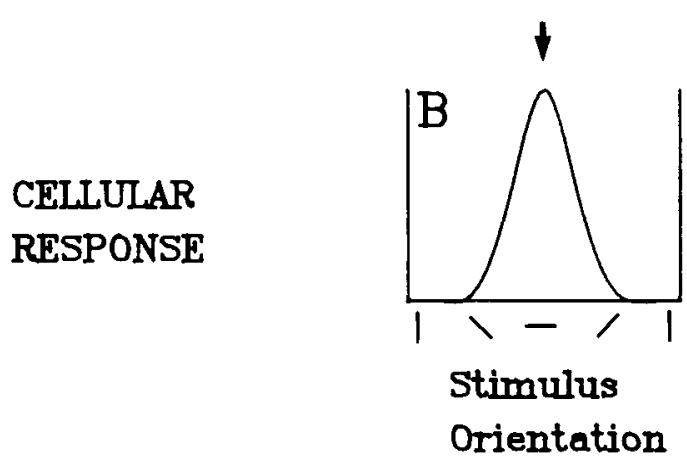

DEPRIVED EYE INPUT

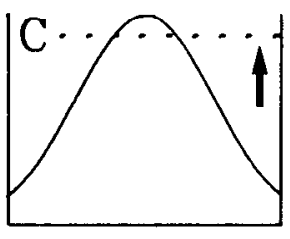

$\downarrow$
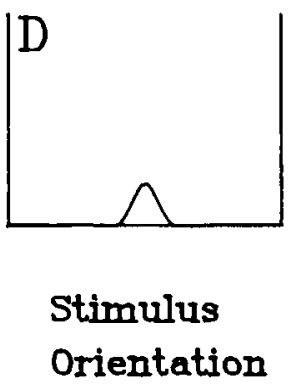

\section{DEPRIVED EYE INPUT (BICUCULLDNE)}
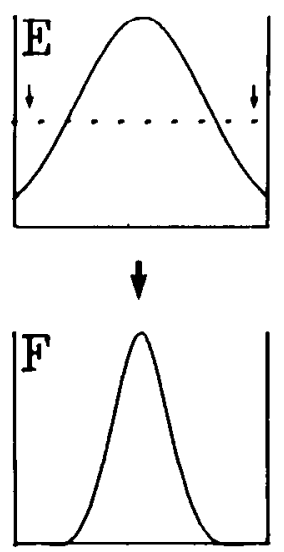

\section{Stimulus \\ Orientation}

Figure 11. Hypothesis formulated to cxplain why bicuculline restorcs responsivencss to the deprived eyc in MD kittens. In this case, inhibitory circuitry

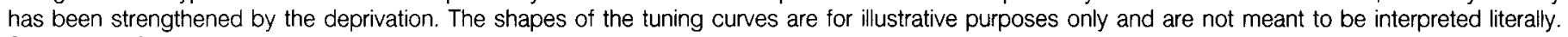
See the text for complete explanation. 


\section{NORMAL INPUT}

\section{SYNAPTIC INPUT}

\section{CELLULAR RESPONSE}
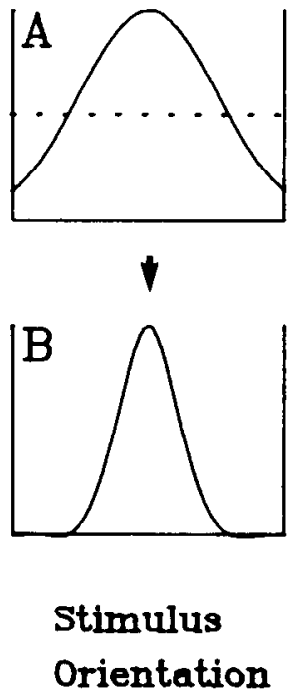

DEPRIVED EYE INPUT

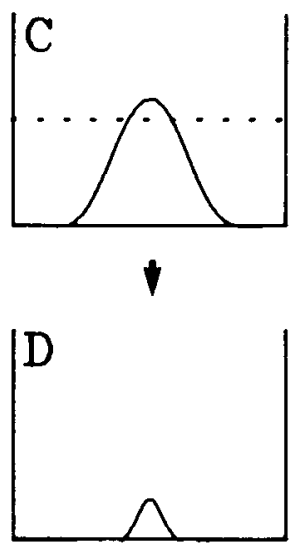

\section{Stimulus Orientation}

\section{DEPRIVED \\ EYE INPUT \\ (BICUCULIINE)}

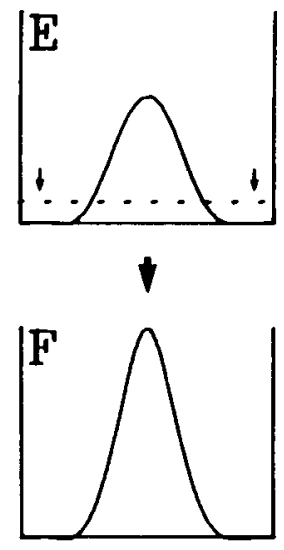

\section{Stimulus \\ Orientation}

Figure 12. An alternative hypothesis to explain why bicuculline restores deprived eye responsiveness in MD kittens. In this case, excitatory connections are weakened by the deprivation. Refer to the text for complete explanation.

even though the respective standard errors are less than $10 \%$ of the means. This is true regardless of whether the enzyme activity is expressed per gram of tissue (wet weight) or per gram of protein. Although we cannot say with certainty that the experimental and control groups are the same with respect to GAD activity, we can, using statistical analysis of power (Welkowitz et al., 1971), calculate the level of confidence that the two populations differ by less than a certain percentage. Thus, for the binocular segments, the data indicate that we can be $80 \%$ confident that the enucleated and control kittens differ by less than $15 \%$ ( $p<0.05$, one-tailed test). Similarly, we can be $71 \%$ confident that MSR and MSL enzyme activities in enucleated kittens differ by less than $15 \%$. If we consider only kittens aged 131 days or less, this confidence level increases to $88 \%$. This is a conservative way to evaluate the data since similar power analysis reveals that we can only be $67 \%$ confident that the right and left binocular segments in control kittens differ by less than $15 \%$ ( $p<0.05$, two-tailed test). It thus seems safe to conclude from the enzyme assay data, together with the immunocytochemical results, that monocular enucleation is not an adequate stimulus for increasing GAD significantly in kitten striate cortex. We interpret this to mean that the density of GABAergic synapses is not changed by MD. ${ }^{\mathrm{G}}$

If this is the case, then what mechanism explains why deprived eye responses are restored in monocularly deprived kittens during bicuculline administration? To be sure, the efficacy of GABAergic synapses could possibly be increased after MD by subtle uitrastructural or biophysical changes in the terminals (Houser et al., 1983), or by postsynaptic changes in GABA recepter density or affinity (Needler et al., 1983). However, there is probably no need to invoke changes in GABAergic connections at all. The only change required to explain the effects of bicuculline (Duffy et al., 1976: Burchfiel and Duffy, 1981) is that deprived eye excitatory afferents become less

\footnotetext{
${ }^{6}$ Of course, the GAD assay data were obtained only from enucleated kittens. However, it would be surprising if other forms of MD, such as lid closure, produced a change in cortical GAD activity that could not be detected after eye removal.
}

effective in driving visual cortical neurons. According to this hypothesis, illustrated in Figure 12, MD has little effect on inhibitory inputs to cells in deprived eye ocular dominance columns (Fig. 12C). The main effect of MD is a decrease in excitatory drive to these neurons, and the net result is a greatly reduced cellular response to stimulation of the deprived eye (Fig. 12D). Under these circumstances, bicuculline nonetheless could unmask the weak excitatory deprived eye inputs (Fig. 12E, arrows) and restore cortical responsiveness to deprived eye stimulation (Fig. 12F).

There is ample evidence that excitatory inputs from the deprived eye are weakened considerably by MD (Singer, 1977; Tsumoto and Suda, 1978; Mitzdorf and Singer, 1980). The inhibitory input to cells in a deprived eye column could be maintained by the open eye if the open eye afferents were to successfully compete for synaptic space on the GABAergic neurons in the deprived eye column. The presence of open eye geniculate afferents in deprived eye columns is one well known consequence of early MD (Shatz and Stryker, 1978; Presson and Gordon, 1982). Alternatively, the inhibitory input could be maintained by the deprived eye itself because, under some circumstances, inhibitory pathways are apparently less affected by deprivation than are excitatory pathways (Singer, 1977). In either case, this hypothesis states that GABAergic inhibition plays only a passive role in the effects of MD. Recently, a re-evaluation of the effects of bicuculline in monocularly deprived kittens by Sillito et al. (1981) has led to this very conclusion.

The stimulus for modification of GABAergic circuitry. A number of investigators studying synapses with an FS morphology in cat visual cortex have remarked about the high degree of interindividual variability in the density of these synapses (Winfield, 1981; Beaulieu and Colonnier, 1983b). This phenomenon might account for some of the variation we encountered with the GAD assay, since all GABAergic synapses have this FS morphology (Ribak, 1978; Freund et al., 1983). The suggestion has been made that this variability might reflect the different visual experience of individual animals (Beaulieu and Colonnier, 1983b). Indeed, dark rearing of kittens can apparently cause a transient increase in GAD activity and GABA receptor binding at 1 month of age (Needler et al., 1983; M. F. Bear and $\mathrm{C}$. Shaw, unpublished observations). In contrast, in the present 
study GAD levels were unchanged at any age, even in the monocular segment contralateral to the enucleated eye. This makes it unlikely that GABAergic synapses are being regulated directly by afferent activity from the thalamus. Thus, the question remains: What regulates the density of GABAergic synapses in cortex?

One condition that appears to increase GABAergic synapse density is denervation. Nadler et al. (1974) and Goldowitz et al. (1982) have presented evidence that GABAergic cells sprout in the molecular layer of the dentate gyrus after entorhinal lesions (however, see Wagner et al., 1983, for alternate interpretation). Similarly, Smith and Ebner (1980) found an increase in the density of FS synapses in turtle cortex after thalamectomy that correlated with an increase in GAD activity. Other examples are increases in GAD in the red nucleus after cerebellar lesions (Nieoullon and Dusticier, 1981) and in the olfactory tubercle after olfactory bulb lesions (Gilad and Reis, 1979). Does this mean that degenerating axons provide a signal for GABAergic cells to sprout? This cannot be the case in all locations because, for example, we found no evidence for an increase in GAD in the denervated lamina of the lateral geniculate nucleus. Similarly, Wilson and Hendrickson (1981) report no difference in the density of FS synapses in the denervated monkey geniculate.

Perhaps there exists a central modulator of GABAergic circuitry. A number of widely projecting systems are in a strategic position to contribute to this regulation; for example, the noradrenergic projection from the locus ceruleus or the cholinergic projection from the basal forebrain. Although this idea may appear to be wildly speculative, we have recenlly found that depletion of cortical acetylcholine in mice will result in a decrease in GAD activity after postoperative periods over 6 weeks (Höhmann, et al., 1985). A state-dependent modulator could explain why dark rearing increases GAD in striate cortex at the same time monocular enucleation causes no change. It is well known that complete darkness can have effects on kitten development that go beyond the visual system (Movshun and Van Sluyters, 1981).

The final elucidation of the factors that regulate GABAergic circuitry will be particularly rewarding since a decrease in cortical GAD contributes to the etiology of epilepsy (Ribak et al., 1979). The present study narrows the search somewhat, since it appears that GABAergic synapses are regulated independently of thalamic activity, at least in kitten visual cortex.

\section{References}

Beaulieu, C., and M. Colonnier (1983a) The number of neurons in the different laminae of the binocular and monocular regions of area 17 in the cat. $\mathrm{J}$. Comp. Neurol. 217: 337-344.

Beaulieu, C., and M. Colonnier (1983b) There are interindividual differences in the numerical density of flat symmetrical (but not round-asymmetrical) synapses in area 17 of cat. Soc. Neurosci. Abstr. 9: 821

Bradford, M. M. (1976) A rapid and sensitive method for the quantitation of microgram quantities of protein utilizing the principle of protein dye binding

Burchfiel, J. L., and F. H. Duffy (1981) Role of intracortical inhibition in deprivation amblyopia: Reversal by microiontophoretic bicuculline. Brain Res. 206: 479-484.

Coyle, J. T., and S. J. Enna (1976) Neurochemical aspects of the ontogenesis of GABAergic neurons in the rat brain. Brain Res. 111: 119-133.

Curtis, D. R., and D. Felix (1971) The effect of bicuculline upon synaptic inhibition in the cerebral and cerebellar cortices of the cat. Brain Res. 34 301-321.

Dreifus, J. J., J. S. Kelly, and K. Krnjevic (1969) Cortical inhibition and $\gamma$ aminobutyric acid. Exp. Brain Res. 9: 137-154.

Duffy, F. H., S. R. Snodgrass, J. L. Burchfiel, and J. L. Conway (1976) Bicuculline reversal of deprivation amblyopia in the cat. Nature 260: 256257.

Einstein, G., T. L. Davis, and P. Sterling (1983) Convergence on neurons in layer IV (cat area 17) of lateral geniculate terminals containing round or pleomorphic vesicles. Soc. Neurosci. Abstr. 9:820.

Emson, P. C., and S. P. Hunt (1981) Anatomical chemistry of the cerebral cortex. In The Organization of the Cerebral Cortex, F. O. Schmitt, F. G Worden, G. Adelman, and S. G. Dennis, eds., pp. 325-346, MTT Press, Cambridge, MA.

Fitzpatrick, D., G. R. Penny, D. Schmechel, and I. T. Diamond (1982) GAD immunoreactive neurons in the lateral geniculate nucleus of the cat and Galago. Soc. Neurosci. Abstr. 8: 261.

Fitzpatrick, D., K. Itoh, and I. T. Diamond (1983a) The laminar organization of the lateral geniculate body and the striate cortex in the squirrel monkey (Saimiri sciureus) J. Neurosci. 3: 673-702.

Fitzpatrick, D., J. S. Lund, and D. Schmechel (1983b) Glutamic acid decarboxylase immunoreactive neurons and terminals in visual cortex of the monkey and cat. Soc. Neurosci. Abstr. 9: 616.

Freund, T. F., K. A. C. Martin, A. D. Smith, and P. Somoygi (1983) Glutamate decarboxylase-immunoreactive terminals of Golgi-impregnated axo-axonic cells and of presumed basket cells in synaptic contact with pyramidal neurons of the cat's visual cortex. J. Comp. Neurol. 221: 263-278.

Gilad, G. M., and D. J. Reis (19/9) Neurochemical plasticity: Increased glutamic acid decarboxylase activity in the olfactory tubercle following olfactory bulb removal during postnatal development. Brain Res. 177: 200-203.

Gilbert C. D., and T. N. Wiesel (1979) Morphology and intracortical projections of functionally identified neurons in the cat visual cortex. Nature 280: 120 125.

Goldowitz, D., S. R. Vincent, J. -Y. Wu, and T. Hokfelt (1982) Immunohistochemical demonstration of plasticity in GABA neurons of the adult rat dentate gyrus. Brain Res. 238: 413-420.

Hamos, J. E., T. L. Davis, and P. Sterling (1983) Four types of neuron in layer IVab of cat cortical area 17 accumulate ${ }^{3} \mathrm{H}$ GABA. J. Comp. Neurol. 217: 449-457.

Hendrickson, A. E., S. P. Hunt, and J. -Y. Wu (1981) Immunocytochemical localization of glutamic acid decarboxylase in monkey striate cortex. Nature 292: 605-607

Höhmann, C. F., M. F. Bear, and F. F. Ebner (1985) Glutamic acid decarboxylase activity decreases in mouse neocortex after lesions of the basal forebrain. Brain Res., in press.

Houser, C. R., M. Lee, and J. E. Vaughn (1983) Immunocytochemical localization of glutamic acid decarboxylase in normal and deafferented superior colliculus: Evidence for reorganization of $\gamma$-aminobutyric acid synapses. J. Neurosci. 3: 2030-2042.

Hubel, D. H., and T. N. Wiesel (1970) The period of susceptibility to the physiological effects of unilateral eye closure in kittens. J. Physiol. (Lond.) 206: 419-436.

Johnston, G. A. R. (1976) Physiologic pharmacology of GABA and its antagonists in the vertebrate nervous system. In GABA in Nervous System Function, E. Roberts, T. N. Chase, and D. B. Tower, eds., pp. 395-412, Raven Press, New York.

Johnston, M. V., M. McKinney, and J. T. Coyle (1981) Neocortical cholinergic innervation: A description of extrinsic and intrinsic components in the rat. Exp. Brain Res. 43: 159-172.

Kratz, K. E., P. D. Spear, and D. C. Smith (1976) Post-critical period reversal of effects of monocular deprivation on striate cortex cells in the cat. J. Neurophysiol. 39: 501-511.

Krnjevic, K., and S. Schwartz (1966) Is GABA an inhibitory transmitter? Nature 211: 1372-1374.

Krnjevic, K., and S. Schwartz (1967) The action of GABA on cortical neurones. Exp. Brain Res. 3: 320-336.

LeVay, S., M. P. Stryker, and C. J. Shatz (1978) Ocular dominance columns and their development in layer IV of the cat's visual cortex: A quantitative study. J. Comp. Neurol. 179: 223-244.

Lund, J. S., G. H. Henry, C. L. Macqueen, and A. R. Harvey (1979) Anatomical organization of the primary visual cortex of the cat: $A$ comparison with area 17 of the macaque monkey. J. Comp. Neurol. 184: 549-618.

MacDonnell, P., and P. Greengard (1975) The distribution of glutamate decarboxylase in rat tissue: Isotopic vs. fluorimetric assays. J. Neurochem. 24: 615-618.

Martin, K. A. C., P. Somaygi, and D. Whitteridge (1983) Physiological and morphological properties of identified basket cells in the cat's visual cortex. Exp. Brain Res. 50: 193-200.

Mitzdorf, U., and W. Singer (1980) Monocular activation of visual cortex in normal and monocularly deprived cats: An analysis of evoked potentials. J. Physiol. (Lond.) 304: 203-220.

Movshun, J. A., and R. C. VanSluyters (1981) Visual neural development. Ann. Rev. Psychol. 32: 477-522.

Nadler, J. V., C. W. Cotman and G. S. Lynch (1974) Biochemical plasticity of short-axon interneurons: Increased glutamate decarboxylase activity in the denervated area of rat dentate gyrus following entorhinal lesion. Exp. Neurol. 45: 403-413.

Needler, M. C., C. Shaw, and M. Cynader (1983) Ontogeny and laminar 
distribution of GABA recepter sites in the striate cortex of normal and dark reared cats. Soc. Neurosci. Abstr. 9: 945

Nieoullon, A., and N. Dusticier (1981) Increased glutamate decarboxylase activity in the red nucleus of the adult cat after cerebellar lesions. Brain Res. 224: 129-139.

Oertel, W. H., D. E. Schmechel, E. Mugnaini, M. L. Tappaz, and I. J. Kopin (1981) Immunocytochemical localization of glutamate decarboxylase in rat cerebellum with a new antiserum. Neuroscience 6: 2715-2735.

O'Leary, J. L. (1941) Structure of the area striata of the cat. J. Comp. Neurol. 75: $131-161$.

Olson, C. R., and R. D. Freeman (1975) Progressive changes in kitten striate cortex during monocular vision. J. Neurophysiol. 38: 26-32.

Patrick, R., and Y. Rendel (1980) pH-induced alterations in dopamine synthesis regulation in rat brain striatal synaptosomes. J. Neurochem. 34: 15061513.

Peters, A., and J. Regidor (1981) A reassessment of the forms of nonpyramidal neurons in area 17 of cat visual cortex. J. Comp. Neurol. 203 685-716.

Presson, J., and B. Gordon (1982) The effects of monocular deprivation on the physiology and anatomy of the kitten's visual system. Soc. Neurosci. Abstr. 8: 4.

Ramón y Cajal, S. (1911) Histologie du Système Nerveux de l'Homme et des Vertébrés, 1972 Ed., CSIC, Madrid.

Ribak, C. E. (1978) Aspinous and sparsely spinous stellate neurons in the visual cortex of rats contain glutamic acid decarboxylase. J. Neurocytol 7: $461-478$.

Ribak, C. E., A. B. Harris, J. E. Vaughn, and E. Roberts (1979) Inhibitory, GABAergic nerve terminals decrease at sites of focal epilepsy. Science 205: $211-214$.

Rutledge, L. T. (1978) The effects of denervation and stimulation upon synaptic ultrastructure. J. Comp. Neurol. 178: 117-128.

Sanderson, K. J. (1971) The projection of the visual field to the lateral geniculate and medial interlaminar nuclei in the cat. J. Comp. Neurol. 143: 101-118.

Shatz, C. J., and M. P. Stryker (1978) Ocular dominance in layer IV of the cat's visual cortex and the effects of monocular deprivation. J. Physiol. (Lond.) 281: 267-283.

Sillito, A. M. (1975) The contribution of inhibitory mechanisms to the receptive field properties of neurones in the striate cortex of the cat. J. Physiol. (Lond.) 250: 305-329.

Sillito, A. M., J. A. Kemp, and C. Blakemore (1981). The role of GABAergic inhibition in the cortical effects of monocular deprivation. Nature 291: 318320.
Singer, W. (1977) Effects of monocular deprivation on excitatory and inhibitory pathways in cat striate cortex. Exp. Brain Res. 134: 508-578.

Singer, W., and F. Tretter (1976) Receptive field properties and neuronal connectivity in striate and parastriate cortex of contour-deprived cats. J. Neurophysiol. 39: 613-630.

Smith, L. M., and F. F. Ebner (1980) Synaptic response in a simple cortical system to thalamic removal: Type of synapse and postsynaptic targets of two different sprouting fiber systems. Soc. Neurosci. Abstr. 6: 328.

Smith, L. M., M. F., Bear, D. E. Schmechel, and F. F. Ebner (1983) GAD immunoreactivity in transplanted mouse neocortex. Soc. Neurosci. Abstr. 9: 771 .

Spear, P. D. A. Langsetmo, and D. C. Smith (1980) Age-related changes in effects of monocular deprivation on cat striate cortical neurons. J. Neurophysiol. 43: 559-580.

Sprague, J. M., and T. H. Meikle (1965) The role of the superior colliculus in visually guided behavior. Exp. Neurol. 11: 115-146.

Sternberger, L. A. (1979) Immunocytochemistry, John Wiley \& Sons, Inc. New York.

Tsumoto, T., and K. Suda (1978) Evidence for excitatory connections from the deprived eye to the visual cortex in monocularly deprived kittens. Brain Res. 153: 150-156.

Tusa, R. J., L. A. Palmer, and A. C. Rosenquist (1978) The retinotopic organization of area 17 (striate cortex) in the cat. J. Comp. Neurol. 177: 213-236.

Vincent, S. R. J. I. Nagy, and H. C. Fibiger (1978) Increased striatal glutamate decarboxylase after lesions of the nigro-striatal pathway. Brain Res. 143: 168-173.

Wagner, G. P., W. H. Oertel, and J. R. Wolff (1983) Entorhinal lesions result in shrinkage of the outer molecular layer of rat dentate gyrus leading subsequently to an apparent increase of glutamate decarboxylase and cytochrome oxidase activities. Neurosci. Lett. 39: 255-260.

Welkowitz, J., R. B. Ewen, and J. Cohen (1971) Introductory Statistics for the Behavioral Sciences, Academic Press, Inc., New York.

Wilson, J. R., and A. E. Hendrickson (1981) Neuronal and synaptic structure of the dorsal lateral geniculate nucleus in normal and monocularly deprived Macaca monkeys. J. Comp. Neurol. 197: 517-539.

Wilson, J. R., and S. M. Sherman (1977) Differential effects of early monocular deprivation on binocular and monocular segments of cat striate cortex. J. Neurophysiol. 40: 892-903.

Winfield, D. A. (1981) The postnatal development of synapses in the visual cortex of the cat and the effects of eyelid closure. Brain Res. 206: 166171.

Wong-Riley, M. (1979) Changes in the visual system of monocularly sutured or enucleated cats demonstrable with cytochrome oxidase histochemistry. Brain Res. 171: 11-28. 